Finally, is criticism of the MRCPsych exam by trainees such a bad thing? Has it already become a sacred cow that should be revered? Some young trainees see it simply as a hurdle to be crossed and forgotten, but APIT regards a periodic re-evaluation of the effect that the exam has on training as being of great importance. Fortunately, senior members of the College are not complacent either and have responded to our letter by organizing another examination forum. Of course, clinical tutors could arrange mock examinations for their candidates, as Dr Srinivasan suggests (this is a well recognized procedure in preparation for the MRCP exam) but it is precisely their failure to do so that led APIT, an organization responsive to trainees' needs, to take the initiative. As to 'regional scientific meetings geared solely to the trainees' needs', it is worth noting that five such meetings have already been held in three Regions. Each was organized by a member of APIT who recognized the shortcomings of the local training and made a constructive attempt to improve it.

Francis Creed

RI CHARd Williams on behalf of $A P I T$

Department of Psychiatry,

London Hospital,

Whitechapel.

REFERENCE

'News and Notes, March 1977, p 11.

\section{DIAGNOSTIC FORMULATION IN THE MRCPSYCh EXAMINATION}

DeAR SIR,

There have recently been two contributions to the debate about the expectations regarding diagnostic formulation in the MRCPsych clinical. The first, on behalf of APIT (Bulletin, April 1979, p 67) precipitated the second which appeared in 'The Scribe's Column' (Bulletin, June 1979, pp 108-9). I should like to add a personal contribution to the discussion. I myself passed the MRCPsych examination in 1977, but I have witnessed several colleagues fail to surmount this obstacle at the first attempt, although knowing that their standard of clinical practice was high.

It seems to me that there are two arguments against providing candidates with explicit guidelines in preparing a diagnostic formulation for the examiners. The first is the 'spoon-feeding' argument. According to this view any candidate aspiring to obtain higher qualification should be able to marshall his facts so as to satisfy any reasonable examiner; to provide a formal scheme for presentation is to 'spoon-feed' less able candidates and possibly to restrict the more able. The second argument is that to force a young psychiatrist to formulate a case in a particular way may have some undue influence on the development of his everyday practice; furthermore, that the 'formulation' thus imposed will be a compromise devised for the examination and thus not suited for ordinary clinical usage. There is a third possible a:gument which is that the members of the Examination Committee could not agree amongst themselves as to what form such guidelines should take. I cannot believe that this is true and I shall thus confine myself to arguments on the first two points.

The 'spoon-feeding' argument really falls down when one realizes that it is not allowed to intrude into the design of the written papers. In the Multiple Choice Paper one is told precisely how to signify one's answers. Even in the essay paper one has a restricted choice of questions, and every good candidate knows that the form of the question dictates the form of the answer. There is still scope for individuality, but the expectations of the question are usually sufficiently restricted to allow the marker to make some attempt at comparison with his ideal answer. Neither can it be claimed that such restrictions in written papers are justified in that written accounts are a lesser skill in everyday practice than clinical assessment; the two are inseparable in providing a proper psychiatric service. If it is correct, as I believe it is, that written examinations should have carefully predetermined expectations as to form of answer, then it must be correct for clinical examinations to be treated in the same way.

What can be said about the possible problem of a scheme devised for 'diagnostic formulation' in examinations being used by trainees in the inappropriate setting of day to day clinical duties? It seems to me that such a scheme is unlikely to be so attractive as to beguile the unwary into applying it indiscriminately. Even if I am wrong in this belief, little practical harm would be done. It has been shown that the relationship between diagnosis and treatment decision is not as strong as might be expected (Bannister et al, 1964; Williams, 1979). In an unpublished retrospective survey of 136 patients with symptoms or signs of depression, I obtained data supporting the assertion of the quoted papers; also my findings lent support to the recommendation in the latter paper that the problem-oriented approach is a useful addition to more traditional formulations of diagnosis. 
Having thus considered the matter I can find no good reason why candidates for the MRCPsych clinical examination should not be given clear instructions as to the-form in which they are expected to present their case to the examiners. Might I therefore suggest that the Examination Committee should issue such instructions to candidates (possibly incorporating the idea of a 'problem list' in the formulation) or that alternatively it should explain to all concerned (both trainers and trainees) why such a step is not desirable or possible.

Midland Nerve Hospital,

S. V. OAKes Senior Registrar

Edgbaston,

Birmingham.

REFERENCES

Bannister, D., Salmon, P., Liebermann, D. M. (1964). Diagnosis-treatment relationships in psychiatry. British Joumal of Psychiatry, 110, 726-732.

Williams, P. (1979). Deciding how to treat-the relevance of psychiatric diagnosis. Psychological Medicine, 9, 179-186.

\section{MULTIDISCIPLINARY TEAM PROBLEMS}

DeAr SiR,

As we are all aware, from time to time, professional relationships in multidisciplinary teams can run into difficulties. Usually these difficulties are resolved at a personal or local level. However, in some circumstances it might help if there could be advice and support from people who are not immediately involved.

The Joint Committee of the Royal College of Psychiatrists and the British Psychological Society has sometimes been able to help by sending representatives of the psychiatric and psychological disciplines to assist in this way. The Committee is asking for this letter to be published in the Bulletins of our professional bodies so that colleagues may know of this facility where there is a severe problem between members of our two professions.

Contact with the Joint Committee may be made through the Chairman at The Royal College of Psychiatrists (the Chairmanship alternates between the two professions) or through the Chairman of a member's own Division of the Royal College of Psychiatrists or British Psychological Society.

G. W. Herbert

Chairman of the Joint Committee

\section{COLLEGE NEWS ITEMS}

\section{THE COLLEGE AND THE GENERAL MEDICAL COUNCIL}

The College's Appointed Member

In accordance with the procedure outlined in the June Bulletin ( $p$ 106), a ballot of members of the College Council has been held, and this has resulted in the election of DR P. H. CONNELL to represent the College on the reconstituted General Medical Council.

\section{Elected Members}

Four members of the College have been successful in the direct elections to the G.M. C. They are DR Katharine Bradley, Dr Farrukh Hashmi, Prof Sir Denis Hill and Prof W. Linford Rees.

Appointed and Nominated Members

Among those appointed by Universities are Prof A. H. Crisp, Prof W. H. Trethowan, Prof W. N.
Kessel and Lord Richardson (Hon. Fellow). The official Nominated Members include SIR HENRY YelLowleEs (Hon. Fellow).

\section{PSYCHOTHERAPY SPECIALIST SECTION:} CHANGE OF VENUE

8.15 pm Wednesday, 10 October, 1979-Dr T. Main-"Ernest Jones: Innovator and Pioneer" at the National Farmers Union, Knightsbridge (Hyde Park Corner), London SWI.

\section{NOTICE TO SUBSCRIBERS}

Starting January, 1980, the Bulletin will be distributed free to Members of the College only. Nonmembers, including institutions, who wish to continue to receive the Bulletin should specifically request it from the printers (Headley Brothers Ltd) and there will be a charge of $£ 3.00$ per annum to cover packing and postage. 